Lili Handel: Sangue, poesia e música do

toucador da puta branca,

texto, coreografia e música original de Ivo Dimchev, 2004

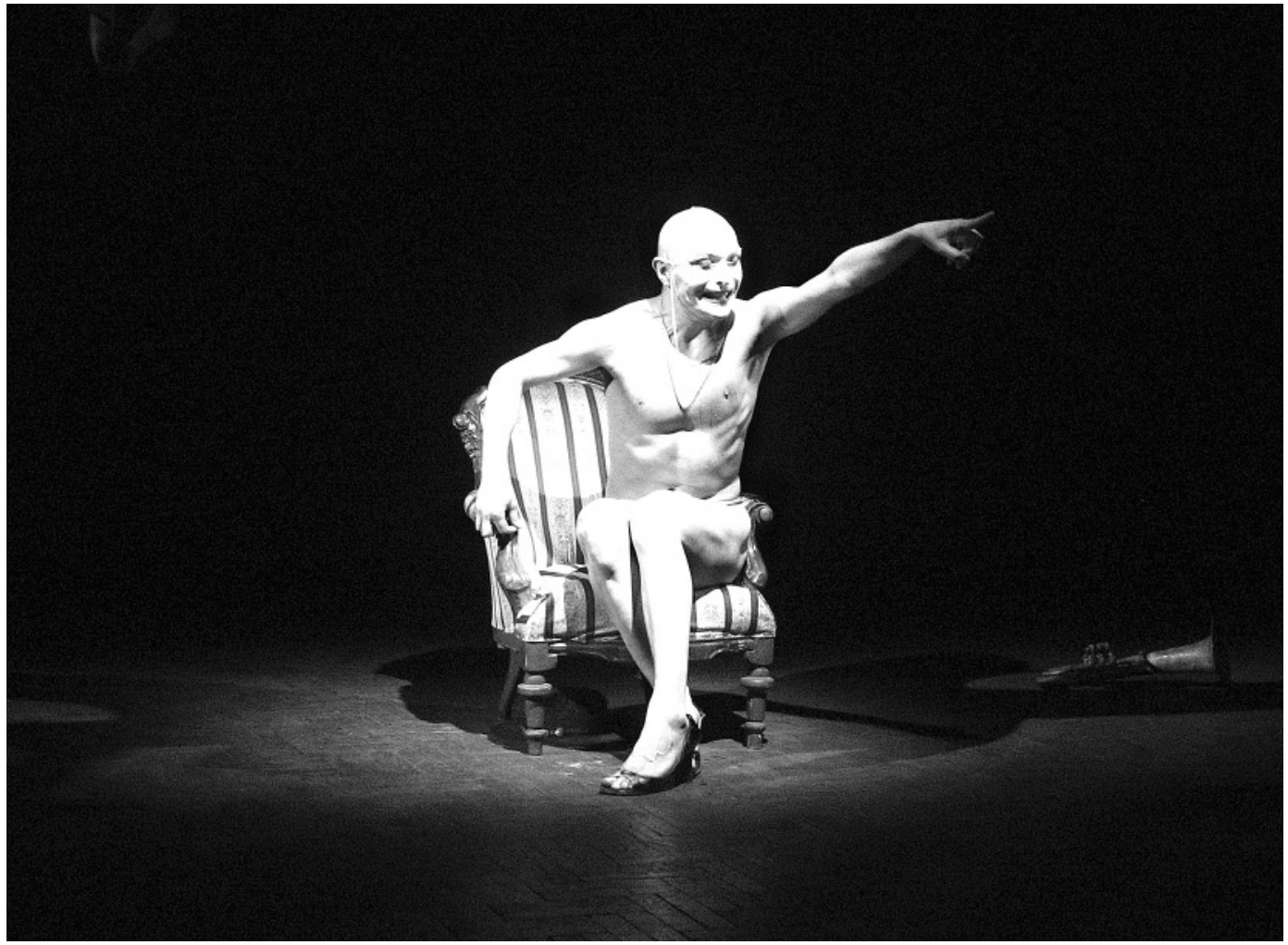

\title{
O corpo como objecto de consumo lvo Dimchev no palco e dentro do corpo
}

\section{Aglika Stefanova}

0 facto de o corpo do actor ser de importância crucial para a existência da arte do teatro é algo passivel de confirmação não só através da breve nota poética de Peter Brook sugerindo que um actor a atravessar um palco vazio é já um acontecimento gerador de uma situação teatral, mas também através da observação mais analítica e comparativa de Kate Hamburger:

\footnotetext{
A imagem em movimento tem uma função narrativa. Assume o lugar da palavra na função narrativa épica. É por isso que no cinema podemos ver cenários ou outros espaços sem personagens; mas o palco do teatro não pode ser mostrado sem personagens. 0 palco tem uma função independente, não pertence à peça e não é parte do texto dramático. (Hamburger 1986: 197)
}

Aglika Stefanov

é ínvestigadora

doutorada pelo

Instituto de Artes

Teatrais da Academia

das Ciências da

Bulgária, é autora de

um livro sobre o

melodrama do ponto

de vista da teoria

(2000) e de um outro

sobre a dramaturgia

búlgara dos anos

noventa (2004)
Assim, de acordo com Hamburger, a peça e o texto dramático são os "donos" do espaço teatral. Mas não nos devemos esquecer que ela está interessada na lógica da literatura e da sua poética. Hoje, sabemos, especialmente após a revelação do pós-dramático por Hans-Thies Lehmann, que o palco foi libertado do texto literário. Outros "donos" tradicionalmente reconhecidos do palco foram as personagens - dramatis personae -, lá colocadas por algum dramaturgo. Durante séculos, foram aceites como "pessoas vivas" e habitantes cénicos por direito. Depois, os semióticos afirmaram que as personagens eram uma mera criação da linguagem e elas foram progressivamente perdendo o estatuto tradicional que detinham no plano histórico.
Actualmente, o palco é dominado pelo corpo do actor, que se apresenta como a única realidade em cena. É só no corpo, como destino teatral final, que depositamos toda a nossa confiança. Desconfiamos completamente da personagem e do seu destino literário. Somos ensinados a ler a linguagem do corpo melhor do que a linguagem da personagem. No mercado teatral internacional, o corpo é hoje, na verdade, o bem mais dispendioso e mais valioso e o destino último da pesquisa em teatro; não há nada para além dele. Excepto o sangue, se transgredirmos os limites da pele.

0 performer búlgaro Ivo Dimchev tornou-se conhecido do público nos últimos anos devido em grande parte ao seu trabalho radical no domínio do teatro físico. Na sua performance de 50 minutos intitulada Lili Handel:Sangue, poesia e música do toucador da puta branca (Lili Handel: Blood, Poetry and Music from the White Whore's Boudoir), ele vai acompanhando a flutuação das cotações do sangue do corpo performativo no mercado internacional. Desde a estreia, que teve lugar na Casa da Dança em Estocolmo em 2004, que Ivo organiza um verdadeiro leilão de sangue durante o espectáculo. E já se vendeu a si próprio mais de 100 vezes em países como a Bulgária, Macedónia, França, Hungria, Estados Unidos, Itália, Turquia, Roménia, Alemanha, Eslovénia, República Checa, Suécia, Canadá e Irlanda. De acordo com a localização geográfica e o estado de espírito do público, ele já conseguiu entre 1 e 40 euros pelas poucas gotas do seu sangue (40 euros foi o melhor 
que conseguiu, em Lille, França). Segundo o próprio artista: "O principal incentivo para criar este espectáculo é a ideia do corpo humano como objecto de consumo físico e estético" (Dimchev 2004).

0 artista está a tentar desenvolver e mostrar o interior constitutivo do corpo - sangue, emoções e estado psicológico - desenvolvendo a linguagem do corpo ao ponto extremo da tortura e da auto-tortura, do consumo e do auto-consumo, do abuso e do auto-abuso. $\mathrm{Na}$ performance É amor (It's Love, 2008), que Ivo Dimchev criou na Academia Dasarts em Amesterdão, o artista esculpia um corpo em materiais têxteis e lama e durante o espectáculo injectava o seu próprio sangue no ombro da escultura, para depois Ihe cortar a cabeça com as palavras "...é amor...", acabando por colocar a cabeça num cacifo. 0 corpo aparecia observado pelo artista como um objecto a ser possuido e dominado; dai também os rituais primitivos de apropriação simbólica de um "outro corpo" que não o seu. Isto representa a dor de ser deixado de fora de forma definitiva, num corpo não transferivel, danificado pela solidão e por hábitos culturais e/ou sociais.

Ivo Dimchev aproxima-se das fronteiras criativas da expressividade do seu próprio corpo. A sua linguagem intensa e concentrada esforça-se por evitar - e nos fazer esquecer - os efeitos do real. 0 corpo surge desnaturalizado, colorido (vermelho) ou coberto com maquilhagem, distorcido num objecto de cultura imitando um produto natural. Esta obra de arte sugere que existia ou que existe ainda um interior natural, mas surge recoberta por camadas de experiência social violenta, imaginação frustrada e loucura especifica.

Ivo exibe, intensamente, o que está a acontecer dentro do corpo como um todo psico-físico. A mente surge aprisionada não só dentro de um corpo específico e de "uso único", mas também dentro de uma cadeia de normas de vida sociais e culturais. Desse modo, e em resposta a essas normas, o corpo executa uma sequência de acções tensas e não naturais. Exibe constantemente reacções que habitualmente ninguém espera de um corpo. Demonstra até que ponto um corpo pode tornar-se não natural, não habitual e não convencional. Na opinião de Tamas Jaszay:

Somos confrontados com uma criatura estranha cujo rosto parece tão artificial como uma máscara de porcelana, um músico cujo único instrumento é o seu próprio corpo. Testemunhamos o resultado trágico e final de um corpo que nos aparece simultaneamente despido e indefeso, exibindo sinais de tortura emocional, mas que, contudo, é belo. (Jaszay 2005)

Na qualidade não de intérprete, mas de criador, Ivo Dimchev dirigiu a performance 28013: Análise teatral dos estudos culturais como fenómeno educativo (28013: Theatrical Analysis of the Cultural Studies as Educational Phenomena, 2006). Trata-se de um trabalho a solo da actriz e mestre em Estudos Culturais Petia Jossifova. Através da linguagem do corpo e de algumas palavras-chave do vocabulário dos
Estudos Culturais, Petia conta-nos a história da sua investigação e dos seus estudos na Universidade de Sófia. 0 espectáculo começa com uma apresentação: "0 meu nome é Petia Jossifova, Mestre em Estudos Culturais...". E exibe a sua experiência académica através de um catálogo original de movimentos físicos.

Nós compreendemos que ela precisava de formar a sua própria visão pessoal sobre Grotowski (o tema do seu trabalho de investigação). Entre os seminários que frequentou, sobre os quais recebemos informação pormenorizada, existirá algum tempo ou espaço livres para os seus próprios pensamentos? Poderão a intuição pessoal e a criatividade ser aplicadas durante o processo educativo, e se sim, quando? Ouvimos a voz do seu orientador, o Professor Stefan Tanev, lendo em voz alta a avaliação do seu trabalho. Ele refere mais vezes o nome de Grotowski do que o nome de Petia. Ela está prestes a desaparecer. Há uma janela e ela salta para a rua. 0 palco fica vazio. Depois, ela chora enquanto escuta o resultado. Provavelmente de felicidade, porque concluiu um período dificil da sua vida; provavelmente porque ela faz agora parte daquela cadeia de autoridades citadas e citáveis; provavelmente porque o seu nome está ligado, embora formalmente, ao nome de Grotowski; provavelmente porque ela é agora a autora de conglomerados de letras e de palavras sem sentido, que gerarão outras; provavelmente porque não se sente mais feliz do que antes?

0 seu número de estudante, 28013, escrito na sua barriga, parece um código secreto, uma senha, que garante o acesso ao território das autoridades. Esses números mágicos confirmam que os seus pensamentos estão correctos e bem orientados pelas autoridades locais, além de corroborados pelas autoridades mundialmente mais famosas, como Grotowski.

Testemunhamos a reacção do seu corpo ao discurso académico. No momento antes da defesa, ela anuncia: "Agora vou demonstrar-vos o meu retrato psicológico". Arrasta-se no chão numa posição não natural, fazendonos lembrar um monstro (mutilado pela violação de alguma doença genética), produzindo sons extáticos em direç̧ão ao céu (assinalando algum prazer extremo ou, bem pelo contrário, um sofrimento extremo - não é claro). Também não é claro se esta forma do corpo e estes sons demonstram uma completa capitulação e desespero face ao discurso científico, após os seus estudos bem sucedidos. Esta expressão física recorda-nos a iconografia da Esfinge, essa mítica guardiã da inteligência e do conhecimento. Deverá Petia ser devorada pela Esfinge no final dos seus estudos, ou irá ela adquirir a sabedoria dessa criatura mítica (uma vez que já assumiu a sua forma), ou ainda, pelo contrário, irá ela conquistar a esfinge como o fez Édipo respondendo correctamente ao enigma sobre "o que é o homem" e "quem sou eu"? Nesta cena, Petia parece como que possuída pelos demónios invisiveis das autoridades que foi obrigada a ler ou a escutar durante os seus estudos. 
Análise teatral dos Estudos Culturais como fenómeno educativo, performance sobre e com Petia losifova, ideia e direcção de Ivo Dimchev,

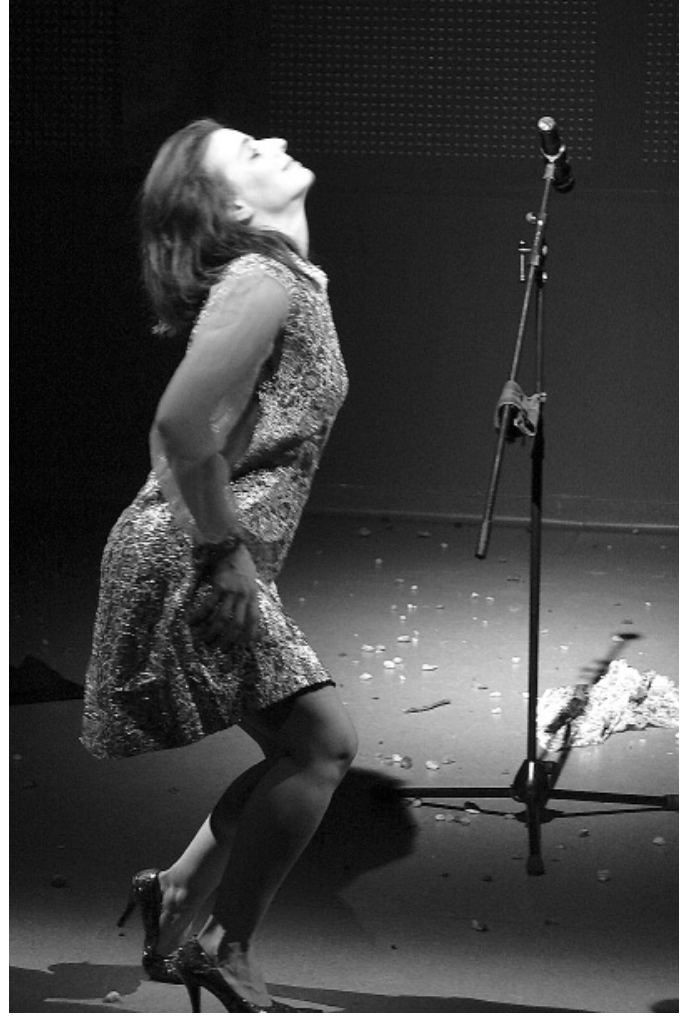

Os Estudos Culturais como fenómeno educativo está provavelmente a criar monstros, já que ninguém aconselha os estudantes relativamente aos modos de se servirem das autoridades, de manterem a distância e de pensarem individualmente. Não há sinais no caminho para a sabedoria e para o auto-conhecimento. Todos são deixados entregues a si próprios, como Édipo.

No final do espectáculo, emerge a questão relativa à aplicação do conhecimento obtido. Petia publica um anúncio listando todos os empregos e profissões para que está habilitada. 0 exercício culmina numa lista absurda, misturando formalmente palavras relacionadas e sons semelhantes. Nessa lista longa e absurda, a pergunta ainda pendente sobre "quem sou eu?" torna-se mais séria do que antes.

Este espectáculo de 50 minutos é integralmente baseado numa experiência documentada; tem um valor não só documental, mas também intimo e pessoal, devido à sinceridade, auto-ironia e vontade de partilhar experiências e pensamentos com o público. Transformase numa pesquisa verdadeiramente informal sobre a mais dificil das questões, repetidamente enunciada desde os tempos antigos.

Todos os espectáculos de Ivo Dimchev prendem-se com a questão de se saber se é o corpo em que estamos aprisionados ou se é antes a nossa imaginação, emoções e sonhos que definem a nossa identidade ou realidade interior. Ivo Dimchev afirma que o corpo tem um interior constitutivo que decide sobre o corpo performativo. Paradoxalmente, a natureza é invisivel, está dentro do corpo, enquanto o corpo é um produto cultural, fechado em algumas práticas sociais. Através do seu corpo, o artista traz para a luz alguns fugazes retratos psicológicos do eu. Ele anda em busca dos equivalentes físicos dos seus estados mentais e emocionais extremos, tenta deixar a natureza falar através do corpo. Ivo Dimchev poderia ser

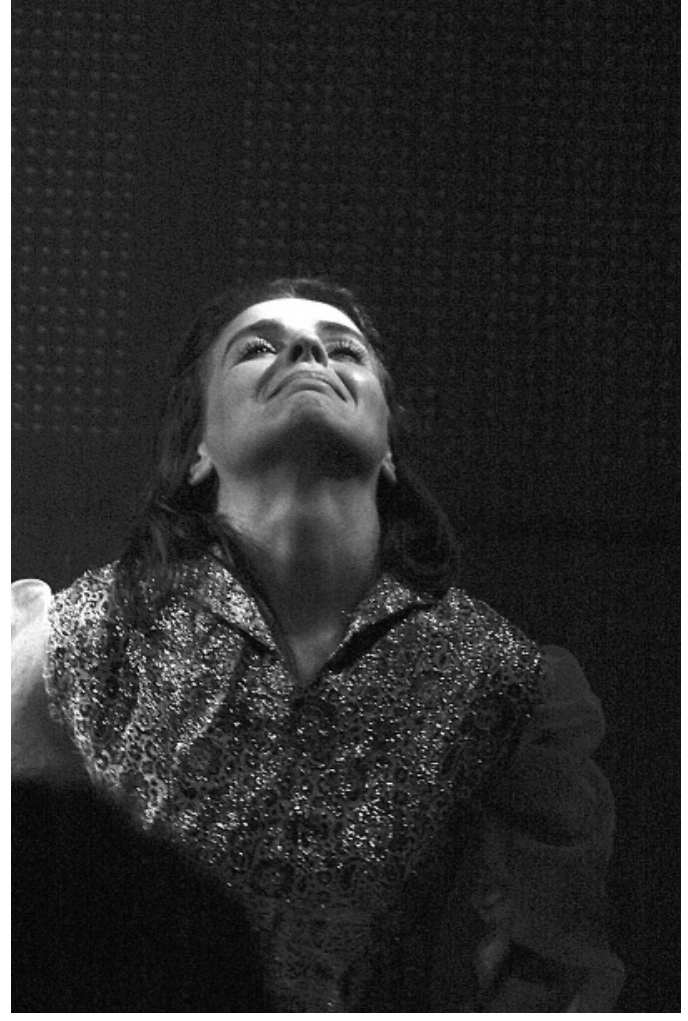

comparado a um pintor expressionista, uma vez que ele trabalha unicamente com os niveis mais elevados das turbulências psicológicas e, na maior parte das vezes, serve-se de contrastes (de movimentos, sons, aparência verbal e não verbal). Ele exibe o seu corpo como um objecto estético, simultaneamente físico e psicológico.

Neste permanente trabalho de pesquisa, o artista serve-se da auto-análise e da observação. Sentimentos espontâneos e ideias são muito importantes para ele; movimentos fixos e improvisados interferem sempre no seu trabalho. 0 seu workshop internacional baseia-se em movimento, voz e trabalho de texto, desenvolvendo competências a nível da criatividade, improvisação, sensação de grupo, parceria, alto nivel de coordenação e capacidade de trabalhar simultaneamente com texto (fixado ou improvisado) e acção fisica (fixada ou improvisada).

Um projecto futuro de Ivo é fazer uma performance com uma equipa internacional de críticos de teatro. Alguns deles dançarão, enquanto outros comentarão a dança e vice-versa, numa espécie de pesquisa sobre o corpo dos críticos e o seu interior constitutivo.

\section{Referências bibliográficas}

DIMCHEV, Ivo (2004), s/título (www.ivodimchev.com, consultado a 12 de Setembro de 2008).

HAMBURGER, Kate (1986), Logique des genres littéraires, Paris, Seuil. JASZAY, Tamas (2005), "Lili Handel" (www.ivodimchev.com/lili.htm, consultado a 12 de Setembro de 2008).

Tradução de Paulo Eduardo Carvalho 